International Journal of Research in Engineering and Innovation
(IJREI)
jJREI

\title{
Transformation technologies for Biogas to biomethane: A review
}

\author{
Dhruv Singh*1, Anjani K Dwivedi ${ }^{2}$ \\ ${ }^{I}$ M.Tech Student, Department of Chemical Engineering, Ujjain Engineering College, Ujjain (M.P.) \\ ${ }^{2}$ Professor, Department of Chemical Engineering, Ujjain Engineering College, Ujjain (M.P.)
}

\begin{abstract}
Biogas is considered as potential option for the replacement of conventional fuels due to its environment friendly and contains less carbon footprint upon use. Conversion of biogas to biomethane leads to increase of applicability such as, transport, heat and electricity. Biomethane from biogas can be obtain from various available technologies such as adsorption, absorption, membrane separation and cryogenic. Out of which physical absorption is considered as economical viable technology till date. In this paper, attempts have been made to discuss various biogas purification technologies, which are widely used all over the world. The widely accepted technologies have been with more prominence on their operation, merits and demerits and their future scope are also discussed.

Keywords: Biogas up-gradation, Water scrubbing, Bio-methane, $\mathrm{CO}_{2}, \mathrm{CH}_{4}$, Biogas.

\section{Introduction}

Biogas from anaerobic digestion of organic wastes or energy crops has proven to be a valuable alternative energy source both climate-neutral and sustainable on a global scale [1]. In times of increasing consequences from global warming and accelerated depletion of fossil resources research concentrates more and more on the supply of sustainable and renewable energy for society and industry. Biogas is experiencing a period of rapid development and biogas upgrading is attracting increasing attention. Consequently, the market for biogas upgrading is facing significant challenges in terms of energy consumption and operating costs. Selection of upgrading technology is sitespecific, case sensitive and dependent on the biogas utilization requirements and local circumstances. Therefore, matching the technology selected for use to specific requirements is significantly important [2, 3].

This chapter explores the state-of-the-art technologies associated with the biogas generation, biogas up-gradation, storage, and utilization. In this paper, attempts have been made to discuss various biogas purification technologies, which are widely used all over the world and major technologies, which are under development or research. The widely accepted technologies have been with more prominence on their operation, merits and demerits and their future scope are also discussed.

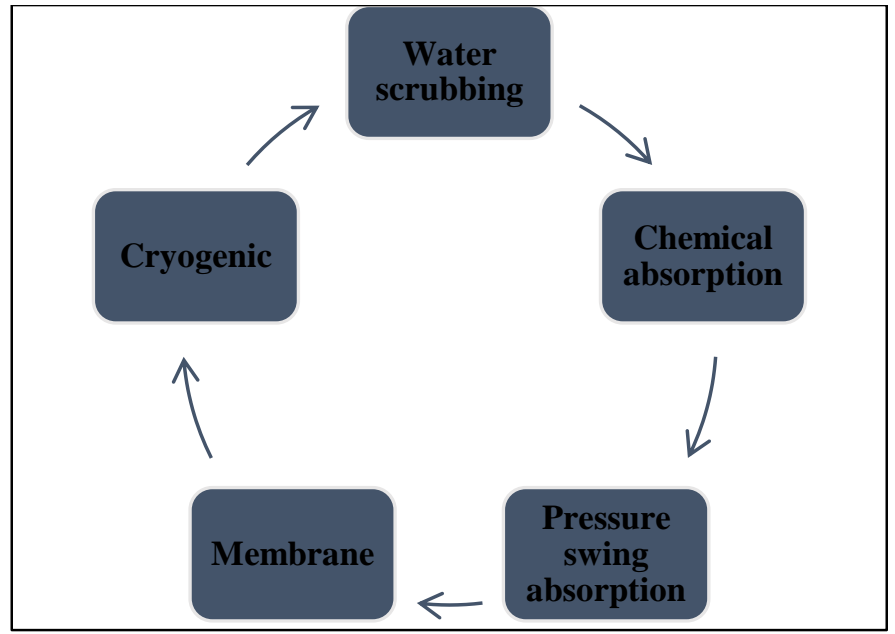

Figure 1: Biogas up-gradation Process

\section{Need For biogas Up-gradation}

As biogas is a mixture of Methane, Carbon dioxide and Hydrogen sulfide out of which Methane is combustible. The calorific value of raw biogas is around $22 \mathrm{MJ} / \mathrm{M}^{3}$ due to presence of Methane. The $\mathrm{CO}_{2}$ and $\mathrm{H}_{2} \mathrm{~S}$ needs to be removed because $\mathrm{CO} 2$ is noncombustible gas which contributes to 0 calorific value in the

*Corresponding author: Dhruv Singh

Email Address: dhruv_singh33@yahoo.com 
biogas. If the raw biogas will be compressed and stored into the cylinders, $\mathrm{CO}_{2}$ not only occupy the storage volume into the cylinder also increases the weight of the gas in cylinder because its density is $1.98 \mathrm{~kg} / \mathrm{M}^{3}$ as compared to density of methane which is $0.656 \mathrm{~kg} / \mathrm{m}^{3}$.The $\mathrm{H}_{2} \mathrm{~S}$ is highly corrosive gas which degrades the life of equipment's at very high rate also it is very harmful for the humans [7]. So both the $\mathrm{CO}_{2}$ and $\mathrm{H}_{2} \mathrm{~S}$ needs to be removed from the biogas after which the calorific value of the Biogas increases to $35 \mathrm{MJ} / \mathrm{M}^{\wedge} 3$ which is known as Bio-CNG. The Bio-CNG is used for vehicular application all around the world. Few such type of plants are also there in India and now government has launched various schemes to promote such type of projects such as SATAT, Gobardhan Yojna etc. Under these schemes these projects will not only gets some financial grants but also reduces the cost regarding import and taxes [8].

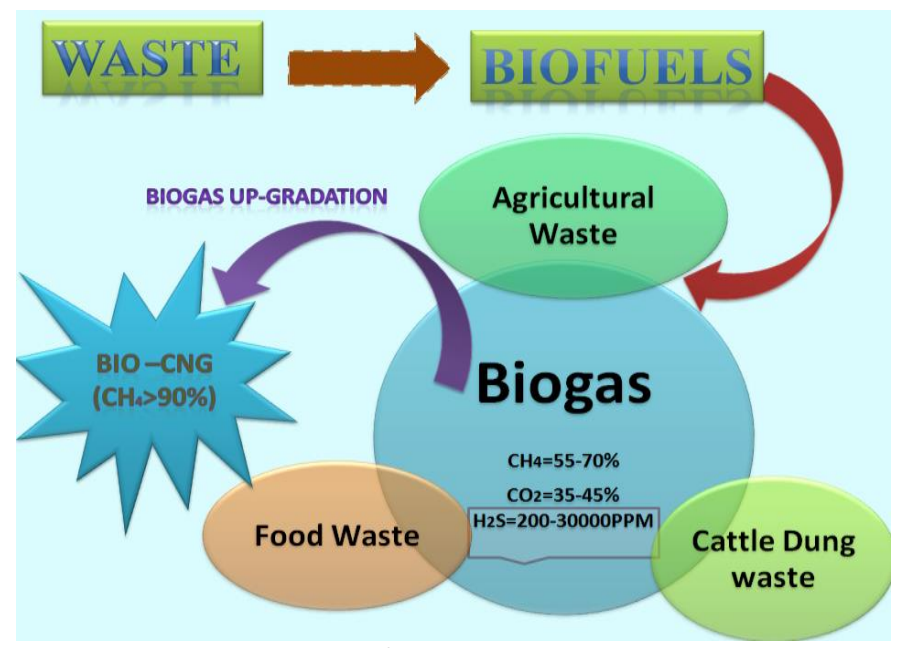

Figure 2: Biogas overview

\section{Biogas Upgrading via Carbon Dioxide Removal Technologies}

The technical features of various upgrading technologies, including water scrubbing, cryogenic separation, physical absorption, chemical absorption, pressure swing adsorption, membrane technology, in-situ upgrading and biological upgrading methods are discussed below.

\subsection{Water scrubbing}

In water scrubbing method raw biogas flow through counter flow of water in the column and it allows water to absorb $\mathrm{CO}_{2}$ leaving biogas with high methane purity up to $98 \%$.This is the most common technology used for biogas upgradation .It has advantages like huge methane purity and simple operation[1].

\subsection{Physical absorption}

Physical absorption is similar to water scrubbing method .It differs only in the type of liquid is replaced by genosorb and PEG in place of water [4].

\subsection{Chemical Absorption}

It works on the principle that $\mathrm{CO}_{2} \mathrm{iS}$ more reactive that $\mathrm{CH}_{4}$ so chemical solution absorbs $\mathrm{CO}_{2}$ and leaves $\mathrm{CH}_{4}$ with high purity. Mono ethanol amine and Di methyl ethanol Amine are used as chemical for absorption in this process.

This technology give purity of $\mathrm{CH}_{4}>99 \%$. The advantage of this technology is the process time is faster as comparison to Physical scrubbing.And drawback of the technology is poisoning of amine and high energy needed [5].

\subsection{Pressure swing Adsorption}

This method comprises of four steps desorption, depressurization, desorption and pressurization. Activated carbon and zeolite are the main adsorbent material for the process. The process gives high methane purity up to $98 \%$.Advantages of the technology is that it is a dry process and less energy consumption. Pretreatment is the main drawback of the technology [6].

\subsection{Membrane Technology}

Separation of biogas using membrane as a permeable material is used. Membrane material is made up of polyimide, cellulose acetate, zeolite and activated carbon. Methane purity obtained from the system is $92-96 \%$.Low membrane selectivity and low methane purity is the major drawback [3].

\subsection{Cryogenic separation method}

Biomethane produced by gradual decrease in the temperature and compressing the biogas methane purity is $97-98 \%$.Disadvantage is high investment and operational cost $[1,5]$.

\section{No. of Biogas up-grading plants}

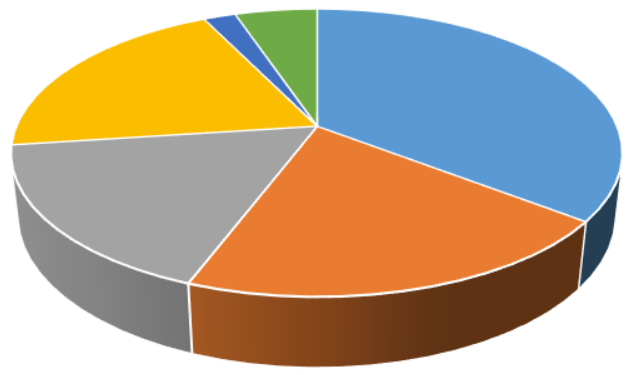

$$
\begin{aligned}
& \text { - Water Scrubbing } \\
& \text { - PSA } \\
& \text { - Cryogenic }
\end{aligned}
$$

\section{- Chemical Scrubbing \\ - Membrane \\ - Organic Physical Scrubbing}

Figure 3: Total no. of biogas upgrading plants of different technologies till 2015[5] 


\section{Conclusions}

It is important to have an optimized upgrading process in terms of low energy consumption and high efficiency giving high methane content in the upgraded biogas. The basic gas cleaning steps including:

- Water vapor removal

- $\mathrm{H}_{2} \mathrm{~S}$ removal

- $\mathrm{CO}_{2}$ removal

- Siloxane and trace gas removal.

This paper will emphasize the biogas cleaning by removal $\mathrm{CO}_{2}$. This review paper briefly discuss the techniques for optimization biogas production as well as the techniques for removing $\mathrm{CO}_{2}$ in order to upgrade the biogas for certain uses[5].

Biogas upgrading is an important process for increasing its fuel value for commercial applications. Upgrading raw biogas to bioCNG enables the use of biogas in vehicles as fuel or for any purpose where natural gas is required. Various technologies, viz. water scrubbing, amine scrubbing, PSA, membrane separation, and cryogenic separation, are available in the market for producing high-quality bio-CNG; however, water scrubbing and PSA are most common owing to the simplicity and effectiveness of the process. Cryogenic upgrading is a good choice because it produces purified biogas in liquid state, but is not commonly used due to its complex operational process. Although analyzing globally, it seems that this technology may break through within a short period of time, resolving the existing problems. The specific investment costs for all the technologies are nearly equal (300-500 Rs $/ \mathrm{Nm}^{3} / \mathrm{h}$ ) for upgrading units with raw gas capacities larger than 800-1000 Nm3 /h [9]. For smaller units, the specific investment costs increase significantly. Thus, the capacity of the plant becomes a very important parameter for deciding the overall economy of producing bio-CNG, which is an efficient and sustainable substitute to $\mathrm{CNG}$.

\section{References}

[1] Sun, Q., Li, H., Yan, J., Liu, L., Yu, Z. and Yu, X., 2015. Selection of appropriate biogas upgrading technology-a review of biogas cleaning, upgrading and utilisation. Renewable and Sustainable Energy Reviews, 51, pp.521-532.
[2] Singhal, S., Agarwal, S., Arora, S., Sharma, P. and Singhal, N., 2017. Upgrading techniques for transformation of biogas to bio-CNG: a review. International Journal of Energy Research, 41(12), pp.1657-1669.

[3] Miltner, M., Makaruk, A. and Harasek, M., 2017. Review on available biogas upgrading technologies and innovations towards advanced solutions. Journal of Cleaner Production, 161, pp.1329-1337.

[4] Adnan, A.I., Ong, M.Y., Nomanbhay, S., Chew, K.W. and Show, P.L., 2019. Technologies for Biogas Upgrading to Biomethane: A Review. Bioengineering, 6(4), p.92.

[5] Sahota, S., Shah, G., Ghosh, P., Kapoor, R., Sengupta, S., Singh, P., Vijay, V., Sahay, A., Vijay, V.K. and Thakur, I.S., 2018. Review of trends in biogas upgradation technologies and future perspectives. Bioresource Technology Reports, 1, pp.79-88.

[6] Sahota, S., Vijay, V.K., Subbarao, P.M.V., Chandra, R., Ghosh, P., Shah, G., Kapoor, R., Vijay, V., Koutu, V. and Thakur, I.S., 2018. Characterization of leaf waste based biochar for cost effective hydrogen sulphide removal from biogas. Bioresource technology, 250, pp.635-641.

[7] Andriani, D., Wresta, A., Atmaja, T.D. and Saepudin, A., 2014. A review on optimization production and upgrading biogas through $\mathrm{CO} 2$ removal using various techniques. Applied biochemistry and biotechnology, 172(4), pp.1909-1928.

[8] Zhao, Q., Leonhardt, E., MacConnell, C., Frear, C. and Chen, S., 2010. Purification technologies for biogas generated by anaerobic digestion. Compressed Biomethane, CSANR, Ed.

[9] Wu, Y.M., Yang, J., Fan, X.L., Fu, S.F., Sun, M.T. and Guo, R.B., 2017. Elimination of methane in exhaust gas from biogas upgrading process by immobilized methane-oxidizing bacteria. Bioresource technology, 231, pp.124-128.

\section{Biographies}

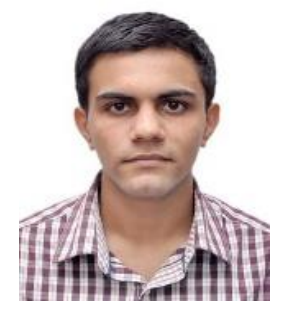

Dhruv is M.Tech student (Environment Management) at Department of Chemical Engineering, Government Engineering College, Ujjain (M.P.).

Email: dhruv_singh33@yahoo.com

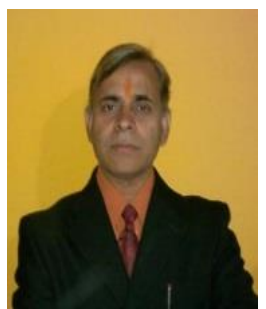

Prof. Anjani Kumar Dwivedi is Professor and Head at department of Chemical Engineering, Government Engineering College, Ujjain (M.P.). He has more than 30 years' experience of research and teaching in chemical engineering. Email: anjanidwivedi108@gmail.com

Cite this article as: Dhruv Singh, Anjani K Dwivedi, Transformation technologies for Biogas to biomethane: A review, International Journal of Research in Engineering and Innovation Vol-4, Issue-1 (2020), 5-7. https://doi.org/10.36037/IJREI.2020.4102. 